\title{
Commentary
}

\section{The Climate Change and Health Adaptation Program: Indigenous climate leaders' championing adaptation efforts}

\author{
Gabrielle Richards (1); Jim Frehs, MA (1); Erin Myers, BA (1); Marilyn Van Bibber (2)
}

Tweet this article

\begin{abstract}
The Climate Change and Health Adaptation Program (CCHAP) is a program within the First Nations Inuit Health Branch of Indigenous Services Canada (which was previously under the responsibility of Health Canada). The CCHAP supports Inuit and First Nation communities in mitigating and adapting to the health impacts of climate change. The impacts of climate change on Indigenous health can be observed in multiple areas including, but not limited to, food security, cultural medicines, mental health and landbased practices. This program seeks to address the needs of climate change and health in First Nation and Inuit communities to support resiliency and adaptation to a changing climate both now and in the future through its emphasis on youth and capacity building. The commentary is based on the Program's eleven years of experience working with and for Indigenous communities and provides an overview of the CCHAP model and the work it has and continues to support. This paper demonstrates three examples of community-based projects to mitigate and adapt to the health impacts of climate change to demonstrate climate change resiliency within Indigenous communities.
\end{abstract}

Keywords: climate change, First Nations, Inuit, community-based, adaptation, mitigation

\section{Introduction}

Environmental changes are both detrimental to human health, and an opportunity to develop adaptive and creative solutions with those who are threatened the most by these environmental shifts. ${ }^{1}$ Amongst those who are critically impacted are First Nation and Inuit communities whose livelihoods and well-being hinges upon the wellness of the land. Cunsolo Willox et al. $^{2}$ describes that Indigenous communities' health and well-being are connected to the land, stating: "[Indigenous] identities, well-being, livelihoods, histories, and emotion-spiritual connection are emergent from the land on which they live” (p. 546). Many Indigenous community members continue to live off the land by hunting, fishing, trapping, and gathering. The physical impacts of environmental changes can be observed by First Nation and Inuit communities by disrupting hunting and game migration patterns which impacts food security, the melting of sea ice and permafrost, lower crop yields, and furthermore, the spread of infectious diseases and more intense and longer heat waves. ${ }^{1,3,4}$ Communities are also impacted emotionally, as Inuit and First Nation communities express that these environmental changes, and subsequent land changes, have impacted community members' identities and livelihoods. ${ }^{2,5}$ These environmental changes are happening at a more accelerated rate than ever before $^{1}$ and are compounded by the impacts that colonization has had on Indigenous communities-further affecting their cultures and their livelihoods. ${ }^{6}$ Colonization has created multiple impacts including the displacement and relocations of First Nations and Inuit people on their land and territory, the hindrance of rights to self-determination, the suppressing of Indigenous languages and cultural

\section{Highlights}

- The Climate Change and Health Adaptation Program (CCHAP) for First Nations South of 60N directly supports First Nations communities to develop and undertake adaptation and mitigation projects to build upon their needs within a changing climate.

- This commentary outlines the CCHAP's work and history, and highlights three cases, in Selkirk First Nation, Arviat and The Mi'kmaw Climate Action, which demonstrate the work these communities have undertaken with support from the Program.

knowledge, and the extraction of land and resources. ${ }^{7}$ These impacts of colonization compounded with climate change have subsequently increased communities' vulnerability to experiencing climate change, critically impacting health and well-being.

Indigenous Knowledge is a key component to climate change resiliency which helps mitigate the health impacts of a changing environment, through place and culture specific knowledge that encourages significant adaptive capacity to health concerns that environmental change has caused. ${ }^{8}$ Indigenous Knowledge is understood as knowledge that has been accumulating and evolving through adaptive processes and cultural transmission between generations of a community, ${ }^{9}$ and "is an understanding of the world and of the human place in the world...a view that explains the mysteries surrounding

\section{Author references:}

1. Climate Change and Health Adaptation Program (CCHAP), Indigenous Service Canada, Ottawa, Ontario, Canada

2. Arctic Institute for Community-Based Research (AICBR), Whitehorse, Yukon, Canada

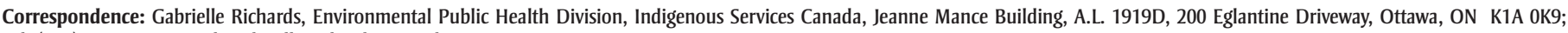
Tel: (343) 540-8011; Email: Gabrielle.richards@canada.ca 
them and, that gives [communities] a sense of place" (Arctic Climate Impact Assessment, 2004). ${ }^{10}$ One key strength of Indigenous Knowledge lies within local contexts of cultural and kinship systems which enables place and culture specific adaptive capacities to be built within communities. ${ }^{8}$ These aspects can lead to stronger mitigation practices amongst First Nation and Inuit communities to adapt to the issues these communities face.

\section{The Climate Change and Health Adaptation Program (CCHAP)}

The Climate Change and Health Adaptation Program (CCHAP) was established in 2008 in response to concerns from First Nation and Inuit communities North of $60^{\circ}$ including Nunatsiavut (Northern Labrador) and Nunavik (Northern Quebec), who were and are being directly impacted by climate change. ${ }^{10,11}$ These communities sought to lead research projects that would positively impact their communities' health and well-being. The CCHAP directly funds Indigenous communities and Indigenous not-for-profit organizations to support communities in conducting their own research in climate change and health, directly building capacity amongst youth and community members. Furthermore, directly funding First Nations and Inuit communities enables communities to use their funds as they see fit to address adaptation and resiliency to climate change. Projects that the CCHAP supports seek to build community capacity and raise awareness around climate change and health while respecting Indigenous sovereignty. Projects thus rely on Indigenous Knowledge and other scientific methods to create tangible change within their communities, and therefore, increase awareness of climate change to reduce risks to health and well-being.

The CCHAP has funded 95 communitybased research and adaptation projects from 2008-2016 in areas such as, food security, water quality, land-based activities, mental health, and cultural medicines among others. In 2016 the program expanded to the southern part of Canada, serving First Nation communities South of $60^{\circ}$. Today, there is one program in the South and one in the North to serve First Nation and Inuit communities in adapting to the changing environments and learning how climate change is impacting health and well-being within communities. ${ }^{*}$

The program embraces First Nation leadership through an Indigenous Selection Committee which reviews projects, offers feedback and makes funding decisions. Transferring the decision-making processes to First Nation and Inuit community representatives ensures that projects undertaken with the CCHAP are truly for communities, by communities. Through the integration of Indigenous leadership, projects undertaken with the CCHAP inherently utilize interdisciplinary approaches that combine Indigenous Knowledge and other scientific approaches to adapt to climate change impacts. The integration of these knowledge streams has enhanced community capacity and encouraged both mitigation and adaptation measures to support communities' well-being. ${ }^{10}$

\section{Three community-based research studies funded through CCHAP}

Below are three case studies that exemplify some of the work the CCHAP supports which provide examples of the breadth and scope of the work Indigenous communities have undertaken since 2008 . These projects represent some of the successes Indigenous communities have had with initiatives undertaken with support from the CCHAP's funding. Each of these projects represents the adaptive capacity of First Nations and Inuit peoples and how their cultural knowledge has led to adaptation and mitigation within a changing climate, increasing communities' resiliency to climate change. Projects supported in Selkirk First Nation, Arviat, and within Mi'kmaw territory offer an understanding of the ways Indigenous communities are adapting to a changing climate and are addressing the associated health impacts of climate change on community health and well-being. The Northern case studies are adapted from the CCHAP North Synthesis Report which is currently under publication, information from the climatetelling.info website and project reports with permission and input from project leads. ${ }^{11,12}$

The Selkirk First Nation was supported by the CCHAP in 2015/2016 and produced multiple outputs, including a video and publications which can be found at the
ClimateTelling website and at the Arctic Institute for Community-Based Research's website. ${ }^{5,11}$ Selkirk First Nation rests centrally in the Yukon Territories where the Yukon River salmon are in dramatic decline. The project undertaken by the Selkirk First Nation focused on the relationship between the land, water and the people who rely on the fish camps for food security and to continue cultural practices that support mental, physical, emotional and spiritual well-being of their people. The community relies on salmon as central to their diet and harvesting of the salmon is at the heart of the Northern Tutchone cultural traditions. With the low returns of salmon, due to climactic changes and industrial pressures on the Chinook salmon life cycle, Selkirk people fear not only the loss of a vital food source, but also the loss of age-old traditions of the fish camps. The fish camps are critical to Selkirk food security and at the heart of transferring Indigenous Knowledge to the next generation of Selkirk people. Therefore, the community wanted to continue the traditions of the fish camps to ensure the health and mental well-being of their community members. This project centered around maintaining food security and Tutchone knowledge and culture while adapting to the threat of climate change. To do this, the research was guided by a community advisory committee, Selkirk Elders and the community. A survey of fish camps conducted by the youth with support of the research leads provided an opportunity for the youth to learn first-hand, the value and role of the summer fish camps while being able to understand the impacts that climate change was having on their lands and community. Despite the lack of fish, the youth learned from Elders the importance of keeping Tutchone traditions strong as an important resource for mental well-being and future challenges. The project identified six key strategies for adapting to the changing climate. This project encouraged youth to connect with their Indigenous Knowledge and the role it has in promoting mental wellness, while also learning about the impacts that climate change is having on their land. This was achieved with on-the-land activities at a winter fish camp for youth, as well as their role in the research process, including through conducting interviews and taking photos, culminating in a Photo

${ }^{*}$ For more information on the CCHAP North please visit: https://www.sac-isc.gc.ca/eng/1536238477403/1536780059794. 
Voice story. This project encouraged youth to gain confidence in their communities' knowledge and raised awareness amongst youth and community members on the impacts that climate change is having on their communities' health and culture. Within the community there is a commitment to keep traditions strong through a series of climate change adaptation strategies, including the role of the fish camps.

Arviat, Nunavut was supported by the CCHAP for four years to undertake a project targeting food security beginning in 2010. The community produced multiple reports and outputs including videos and publications which can be found on the ClimateTelling website. ${ }^{11}$ In Arviat, Nunavut, the community developed a project targeting food security that was funded. The purpose of this project was to revitalize the practices of local harvesters and hunters which were seemingly displaced through social and cultural dislocation over the last 40-50 years. This dislocation led to greater safety concerns out on the land, and more of the hunted animals wasted as Indigenous Knowledge was discouraged by colonial practices. In addition, many community members developed diabetes due to reliance on store bought food, an expensive and lesshealthy alternative to country food. ${ }^{12}$ Therefore, the community developed a project by discussing and interviewing Arviat Elders who grounded the project in Inuit values and Indigenous Knowledge, ensuring that the project was culturally appropriate and followed cultural protocols. In these interviews, Elders described the value of 'food sharing' and therefore invested in a community freezer. The next phase explored the options for producing local and healthy foods. To do so, the community developed a composting system and used seaweed at fertilizer. After this, the community worked towards building local capacity to run the greenhouse. Lastly, the project furthered engagement within the community to ensure that a sustainable method of food production could continue. Each of these community-led initiatives built community capacity and supported the revitalization of Indigenous Knowledge. This has resulted in the reintegration of knowledge systems along with new innovations, such as a greenhouse, to ensure community members can be food secure. These initiatives are still strong today, resulting in the Young Hunters' Programming to teach youth hunting skills and several short films and articles which have documented this community's journey. This project is one example of the types of projects which support First Nation and Inuit communities to develop local food systems that are environmentally friendly, produce healthy food options, and are culturally appropriate.

As the program moved to include the southern part of Canada in 2016, Indigenous communities disclosed to the CCHAP that extreme weather events are impacting health and well-being within these communities. Climate change has resulted in increased extreme weather events, including forest fires and floods ${ }^{13}$ which disproportionally impact Indigenous communities, particularly rural and coastal communities. ${ }^{14}$ The CCHAP supported the Confederacy of Mainland Mi'kmaq's Mi'kmaw Conservation Group (later moved into the Mi'kmaw Climate Action Program) in Nova Scotia in a project that addressed emergency management in six different Mi'kmaw communities. This project conducted research, engaged community members, developed needs assessments and reported on the state of emergency plans. The project supported Mi'kmaw communities in developing emergency management measures that incorporated Indigenous Knowledge of health and safety. The project looked at the physical, mental, emotional and spiritual impacts of climate change, emergency events, and emergency management on the health of community members. Through speaking with community members, including, youth and Elders, the Mi'kmaw Climate Action Program gathered information on their specific concerns and needs in the case of emergency due to extreme weather events. The project also brought together Elders with youth through workshops to share knowledge and to encourage passing along skills that can build capacity and increase resiliency, through future activities such as creating canoe paddles and other crafts and activities to learn emergency skills. These skills can connect the youth to the land and help them learn about climate change and how that will impact extreme weather events.

\section{Conclusion}

These three projects that the CCHAP supported represent community led initiatives that support climate change resiliency amongst First Nation and Inuit communities.
These projects were chosen to represent the resiliency of First Nation and Inuit communities and community-based initiatives that have positioned these communities at the forefront of both climate change challenges and adaptation. These projects undertaken demonstrate the importance of localizing adaptation and mitigation measures, specifically within food systems and emergency management. These projects developed with the framework of local, Indigenous Knowledge, to build capacity within communities.

Engaging youth and Elders to respectively learn and pass along Indigenous Knowledge from generation to generation strengthens communities' resiliency and helps ensure that the projects and initiatives are sustainable as capacity within the community and amongst youth are built. Through both peer and professional training each project builds capacities in different areas, such as, research and interview skills, technological skills and skills on the land. These skills are built through the passing of knowledge between generations, which is crucial in ensuring sustainability for our future, a future which youth represent. The projects supported by the CCHAP leverage First Nation and Inuit knowledge to build adaptive capacities within a changing climate that address communities' health concerns. It is through these efforts that Indigenous communities can share both their visions and concerns for the seven generations to come.

\section{Acknowledgements}

The CCHAP would like to thank the project leads of each of the case studies for allowing us to highlight their work and providing their input on this manuscript.

\section{Conflicts of interest}

The authors declare no conflicts of interest.

\section{Authors' contributions and statement}

Gabrielle Richards works at the Climate Change and Health Adaptation Program and contributed to the writing of this commentary with Jim Frehs and Erin Myers who approved the manuscript and added their comments to ensure that the program was reflected accurately in the manuscript. 
Marilyn Van Bibber critically revised the manuscript and contributed the case study on Selkirk First Nation.

The content and views expressed in this article are those of the authors and do not necessarily reflect those of the Government of Canada.

\section{References}

1. Watts N, Amann M, Ayeb-Karlsson S, et al. The Lancet Countdown on health and climate change: from 25 years of inaction to a global transformation for public health. The Lancet. 2018;391(10120):581-630.

2. Cunsolo Willox A, Harper SL, Ford JD, et al. "From this place and of this place:" climate change, sense of place, and health in Nunatsiavut, Canada. Soc Sci Med. 2012;75(3):538-47.

3. Ford JD, Bolton K, Shirley J, Pearce T, Tremblay M, Westlake M. Mapping human dimensions of climate change research in the Canadian Arctic. Ambio. 2012;41(8):808-22.

4. Kwiatkowski RE. Indigenous community based participatory research and health impact assessment: a Canadian example. Environ Impact Assess Rev. 2011;31(4):445-50

5. Arctic Institute of Community-Based Research. Projects [Internet]. Whitehorse (YT): Arctic Institute of CommunityBased Research; 2017. Available from: https://www.aicbr.ca/projects/

6. Kress M. Sasipihkeyihtamowin 1: Niso Nehiyaw Iskwewak. Canadian Woman Studies. 2015;31(1):52-64.

7. Tuhiwai Smith L. Decolonizing methodologies: research and Indigenous Peoples. London (UK): Zed Books; 2012.

8. Ford JD. Indigenous health and climate change. Am J Public Health. 2012;102(7):1260-6.

9. Cuerrier A, Brunet ND, Gérin-Lajoie J, Downing A, Lévesque E. The study of Inuit knowledge of climate change in Nunavik, Quebec: a mixed methods approach. Hum Ecol. 2015;43(3): 379-94
10. Abele F, Gladstone J. Health Canada - Climate Change Health Adaptation Program: synthesis report and impact analysis [Internet]. ClimateTelling; 2016. Available from: http://www .climatetelling.info/uploads/2/5/6/1 /25611440/cchap_final_report.pdf

11. ClimateTelling. ClimateTelling. An Indigenous community portal for climate change and health [Internet]. 2017. Available from: http://www .climatetelling.info

12. Health Canada. Community voices on climate change and health adaptation in northern Canada: summary report of Health Canada's Climate Change and Health Adaptation Program for northern First Nations and Inuit communities [Internet]. Ottawa (ON): Health Canada; 2011. Available from: http: //www.climatetelling.info /uploads/2/5/6/1/25611440/final _summaryreport_eng_sm.pdf

13. Intergovernmental Panel on Climate Change (IPCC). Global warming of $1.5^{\circ} \mathrm{C}$. An IPCC Special Report on the impacts of global warming of $1.5^{\circ} \mathrm{C}$ above pre-industrial levels and related global greenhouse gas emission pathways, in the context of strengthening the global response to the threat of climate change, sustainable development, and efforts to eradicate poverty. Summary for policymakers [Internet]. Switzerland: World Meteorological Organization; 2018. Available from: https://www .ipcc.ch/site/assets/uploads/sites/2 /2018/07/SR15_SPM_High_Res.pdf

14. Durocher L, Kuiack T. The long road home: a global perspective on evacuees. Communication presented at the Canadian Risk and Hazards Network (CRHNet) Symposium, 2017, Halifax. 